\title{
Land use in product life cycles and its consequences for ecosystem
} quality

\section{Journal Article}

Author(s):

Koellner, Thomas

Publication date:

2002

Permanent link:

https://doi.org/10.3929/ethz-b-000423085

Rights / license:

In Copyright - Non-Commercial Use Permitted

Originally published in:

The International Journal of Life Cycle Assessment 7(2), https://doi.org/10.1007/BF02978857 


\section{Land Use in Product Life Cycles and its Consequences for Ecosystem Quality *}

Land use is an economic activity that generates large benefits for human society. However, as a side effect, it has caused many environmental problems throughout history and still does today. Some examples of these are endangerment of species, nutrification of lakes and rivers, loss of fertile soil, and impact on landscapes' aesthetics. All of these impacts put pressure on regional ecosystem quality. In this thesis, I focused on biodiversity, which is conceptualised as an important part of ecosystem quality. International treaties the most important being the Convention on Biodiversity stress biodiversity's intrinsic value as well as its value for the functioning of the world's ecosystem.

Life Cycle Assessment (LCA) is a tool for addressing the life cycle of a product with respect to environmental problems. However, land use and its consequences for ecosystem quality still aren't adequately taken into account in LCA. My objectives were (i) to develop a method of assessing land use impacts on biodiversity which is suitable for LCA, (ii) to make the general method operable using empirical information on species diversity, and (iii) to apply calculated characterisation factors in a simple case study.

In Life Cycle Impact Assessment (LCIA), characterisation factors are used to weight an environmental intervention with respect to its potential to damage the defined safeguard subject. To develop characterisation factors for land use, a modelling approach was applied. The modelling was split up into different stages. First, a qualitative model was developed linking land use activities and impacts on ecosystem quality. The rather general safeguard subject, ecosystem quality, was split up into more specific attributes (biodiversity, ecosystem functions, and ecological resources). Next, land use impacts on local and regional species diversity were quantified. The use of effect-damage curves allowed observed effects on species diversity to be transformed into potential damage/benefits. The characterisation factor ecosystem damage potential (EDP ${ }^{\text {sp-div }}$ ) refers to those damage/benefits. Finally, local and regional damage potentials were condensed into a single factor.

I developed a set of diverse characterisation factors, EDPspdiv, which made it possible to take into account different background situations on the regional scale. In addition, differences in sensitivity to land use activities of all of the species and of those species which are already threatened could be considered. The characterisation factors were calculated according to a linear as well as a nonlinear model. Data uncertainties were assessed with a Monte-Carlo simulation.

The results of the analysis show that land use types differ remarkably in their local species richness and their corre-

* Köllner T (2001): Land Use in Product Life Cycles and its Consequences for Ecosystem Quality. PhD thesis No. 2519, University St. Gallen sponding local $E D P^{s p-d i v}$ value. Detrimental land use types with low species numbers (0-20 species/0.01 ha) are continuous urban area, conventional arable land, intensive meadow, and sports facilities. Moderate types ( $20-40$ species $/ 0.01$ ha) are semi-natural broad-leafed forest, organic arable land, and green urban area. Beneficial types (40-60 species $/ 0.01 \mathrm{ha}$ ) are industrial fallow, agricultural fallow, organic meadow and forest edges. Regional EDPsp-div factors show a similar picture (high and low-intensity artificial land are very detrimental to regional species richness, highintensity agriculture and high-intensity forestry are detrimental, low-intensity agriculture and low-intensity forestry are beneficial). Overall, characterisation factors were calculated for 30 land use types and eight types of intensity of land use, allowing a varied impact assessment of land use.

The application of developed EDPsp-div factors is rather simple. In order to calculate the total damage of a land use activity, the area of the specific land use type, its duration of use, and its specific characterisation factor are multiplied. An exemplary case study assessing the land use of agricultural products was conducted for vegetables. Vegetables' life cycle consists of 4 phases: production, storage, transportation, and packaging. Application of the characterisation factors resulted in a change of the ranking of the alternatives investigated.

For operational calculations of EDPsp-div, plant species diversity was chosen as the indicator for biodiversity. Although taking other species groups into account in addition could change the detailed results, the overall ranking of the land use types is expected to be robust. If threatened species were weighted more than non-threatened species, near-to-natural land use types (e.g., natural grassland) would then benefit in the ranking. In general, the local EDPsp-div factors calculated can be applied to the assessment of land use in Western European countries. However, the validity of the results decreases as the distance to the study region (Swiss Plateau, Germany) increases. In contrast, the regional factor is based on a regression analysis using data from the Swiss Alps. Therefore, application of the results is limited and should only be used for alpine regions.

Keeping the limitations described above in mind, one can conclude that this book improves damage-oriented methods for Life Cycle Impact Assessment, such as the Eco-indicator 99, in assessing land use. In the future, however, it would be advisable to include empirical information covering a wide geographical range.

Dr. Thomas Koellner (Dipl. Biol.) Swiss Federal Institute of Technology Natural and Social Science Interface (ETH-UNS) Haldenbachstr. 44, ETH-Zentrum HAD F2 $\mathrm{CH}-8092$ Zurich / Switzerland koellner@uns.umnw.ethz.ch; http://www.uns.umnw.ethz.ch/pers/koellner 